\title{
KNOWLEDGE-BASED FIS AND ANFIS MODELS DEVELOPMENT AND COMPARISON FOR RESIDENTIAL REAL ESTATE VALUATION
}

\author{
Sukran YALPIR ${ }^{1, *}$, Gulgun OZKAN ${ }^{1}$ \\ ${ }^{1}$ Department of Geomatics Engineering, Faculty of Engineering, Selcuk University, Konya, Turkey
}

Received 13 April 2016; accepted 8 March 2017

\begin{abstract}
There has been an increasing concern on the development of alternative approaches to overcome the problems and deficiencies that occur during the application of real-estate valuation methods. This study was established to investigate the usability of the expert knowledge based fuzzy logic methodology in determining real-estates values. In addition, valuation with the Adaptive Neuro-Fuzzy Inference System (ANFIS) method provided model comparison. Samples were administered a questionnaire for the parameters planned for these models regarding the parameters that affect real estate values. To make value estimations for the Fuzzy Inference System (FIS) model by using the parameters obtained from the questionnaire analyses, the criteria that produced the best results were acquired from the various criteria alternatives. An algorithm was created and the valuation process for real estate was performed using the FIS in Konya/Turkey. As a result of poll studies the area, age, floor conditions, physical properties and location of the real-estate property were considered as the input variables and the market value as the output variable. The memberships were established with poll analysis and were rule based on expert knowledge. The model structure was formed by using the Mamdani structure in the MATLAB fuzzy toolbox. Model prediction performance was evaluated statistically with the Mean Absolute Percentage Error (MAPE) and a high accuracy of the model results to the market values indicated the reliability of the established model for residential real-estate valuation.
\end{abstract}

Keywords: residential real-estate, valuation, market value, Mamdani, model establishment, fuzzy.

\section{Introduction}

The International Valuation Standards Committee (IVSC) released the international valuation standards in 2005 (IVS), and the market value was defined as the estimated amount of money for which a property should be exchanged, on the date of the valuation, between a willing buyer and a willing seller, in an arm's-length transaction after proper marketing wherein the parties acted knowledgeably, prudently and without compulsion (IVS, 2005). The market price is formed when demand and supply curves intersect. It is influenced by many objective and subjective factors and very rarely is equal to the market value, because the market of real estate is not an ideal market. The market price of a real estate property reflects many subjective factors therefore a real estate assessor must find the most objective way to arrive at the asking price (Kontrimas \& Verikas, 2010).

The differences are unavoidable in the valuation of real estate price variability from person to person. But the valuation process should be based on objective (more re- alistic, tangible, and visible) facts by keeping away from subjectivity. Personal preferences come into prominence in addition to objective facts. For example: a family with young kids or an elderly person may prefer the ground floor (to escape quickly in case of fire) while a 25 years old single man/woman may prefer the $10^{\text {th }}$ floor. Such personal preferences should not affect the valuation models. The exclusion of personal approaches from the valuation process will enable the standardization of real estate valuation. Thus, possible price confusions will have been prevented.

The criteria that affect the property value should be determined before beginning the real estate valuation processes, since they vary due to regional characteristics (Lewis, Ware, \& Jenkins, 2001). Therefore, the selection of the valuation method becomes more complicated due to the large number of criteria. Furthermore, each country has different cultural and socio-economic structures; therefore, it is difficult to define a worldwide standard

${ }^{\star}$ Corresponding author. E-mail: sarici@selcuk.edu.tr 
linear model. The model should be flexible and adaptive, such that all input variables can be selected and modified by the user.

In the literature, different methods have been suggested to estimate residential real estate's market value. These are classified into three groups as classical, statistical and advanced. The classical methods are usually based on the comparison principle. Statistical methods establish a mathematical relationship between input and output variables and the advanced valuation methods utilize computer technologies (Pagourtzi, Assimakopoulos, Hatzichristos, \& French, 2003). Classical methods are divided into three groups as comparison, revenue and cost method. They are the most preferred methods in Turkey and throughout the world.

Implementation of classical methods is easy. However, since they can be applied as indexed to the real estate, whose value is to be determined, these methods are inadequate when there is more than one real estate. Especially, the applicability of classical methods are insufficient when creating value maps.

Statistical methods can be applied as multi-regression and nominal methods which are similar to each other in their mathematical structure. In both cases, the criteria that affect the value are derived in the form assignment of the weight coefficient. In order to test the accuracy of the method developed, the multi regression method is used as a comparison in the literature (Din, Hoesli, \& Bender, 2001; Mak, Choy, \& Ho, 2010).

Since advanced valuation methods can be applied using computer technologies, it is possible to analyze particularly large amounts of data. The aim of advanced valuation methods is to equip computers with the ability to think like a human being (artificial intelligence techniques). These are the methods developed to estimate the unknown using the known. Fuzzy logic (Fuzzy Inference System (FIS) and Adaptive Neuro-Fuzzy Inference System (ANFIS)), artificial neural networks (ANN) and genetic algorithms (GA) are the artificial intelligence methods most commonly used in real estate valuation. GA models found more successful than Multiple Regression Analysis (MRA) model (Fischer \& Lai, 2008; Fischer, 2008). There has been a limited number of studies on fuzzy logic (Heine, 2001; Kontrimas \& Verikas, 2010; Mert \& Yilmaz, 2009; Kusan, Aytekin, \& Özdemir, 2010). Some researches present the comparisons of various methods, in which the fuzzy logic technique achieved the closest market value among the others (Bonisssone \& Cheetham, 1997; Lokshina, Hammerslag, \& Insinga, 2003). For example, it was investigated that the model created on FIS was more successful than the model created on ANN (Yalpir \& Ozkan, 2008). Yalpir and Ozkan (2011) have also evaluated residential real-estates at Konya/Turkey, using fuzzy logic (FIS) and compared to MRA techniques. Correlation $\left(\mathrm{R}^{2}\right)$ and root mean square error (RMSE) between predicted and real values were 0.85 and 19 for FIS, 0.64 and 30 for MRA, respectively. Some accurate and efficient hybrid models for valuation of real estate were developed for real estate price prediction (Sarip, Hafez, \& Daud, 2016). Three different modeling approaches were applied to model the price prediction namely, ANN, ANFIS and fuzzy least squares regression (FLSR), their real estate value estimation performances were compared, and as a result FLSR approach was found more successful on hybrid methods (Sarip \& Hafez, 2015; Gonzalez, 2008).

Fuzzy Logic controls unclearly defined systems by sorting them with a commonsensical approach. Fuzzy Logic is especially appropriate for systems whose mathematical model is very difficult to obtain (Sen, 2001). It is an effective method in processing text variables. Every logical system can be expressed as fuzzy. The information is in terms of text expressions like "large", "small" and "very small". Instead of thinking based on definite reasons, Fuzzy Logic is thinking based on approximate values. The fuzzy inference process is performed with the rules described within the text expressions. The variables expressed as true or false in classical logic can be graded definitely between 0 and 1 in Fuzzy Logic.

Many numerical and text variables can be defined with fuzzy logic methodology in the valuation of the real estate. The input variables are the factors that affect the value of real estate, and the output variable is the real estate's calculated market value. Fuzzifying is the process of introducing input and output variables to the computer, and the rule base is the rule writing process of the fuzzified memberships which should be done by specialists.

FIS can be explained as strong tool to simulate nonlinear behaviors by employing the fuzzy logic and linguistic fuzzy rules. FIS-employing fuzzy "If-Then rules" can easily model the qualitative aspects of linguistic human knowledge and reasoning processes without precise quantitative analyses (Ho, Zhang, \& Xu, 2001). The most common and well-known FIS approaches are Takagi-Sugeno (Takagi \& Sugeno, 1985) and Mamdani Methods (Mamdani \& Assilian, 1975).

Although the Sugeno fuzzy inference system is not sensitive to human intuition, it has been more frequently preferred to the Mamdani method in real estate valuation practices (Kusan et al., 2010) because of its simplicity compared to Mamdani where expert knowledge is required in the determination of membership and rule bases. The numbers of input, output and subset are important for the Sugeno inference system where an increase in the numbers necessitates a longer training time and produces a more complex structure for Sugeno to be applied to real estate valuation. Sugeno generates non-fuzzy output, meaning an output corresponding to the data set, whereas Mamdani incorporates expert knowledge that enables the system to predict output for different data values. This is important in real estate market to predict real estate values in accordance with human intuition where Mamdani is promising (Sygnowski, Trawinski, \& Zgrzywa, 2008; Mert \& Yllmaz, 2009) because available data are often uncertain. Real estate valuation needs to be modeled with a tractable approach embodying subjective components. Regional and socio-economical conditions are the most 
important factors that affect value and are expected to be evaluated at a more efficient level with Mamdani fuzzy inference system.

Real estate valuation is required for many activities such as:

- renting and leasing processes,

- determination of tax assessments related to real estate,

- valuation of the mortgage wallets and guarantees,

- other conditions that are required to be valuated by the law.

Due to use of different methods in these activities, it is not surprising to encounter more than one derived value for one real estate property. For example, differences can be observed between the subject-to-taxation value of a property and its trade (market) value and expertise value (taken as basis in mortgage loans). For this reason, it turns out to be necessary for real estate to have one single real value.

In this study, a Mamdani fuzzy inference system was established for the real estate valuation and the applicability of the fuzzy logic methodology was investigated. The study also defined the criteria appropriate for residential real estate. The model verification data was collected from selected regions of Konya metropolitan area (Turkey). Memberships of the model were structured with a poll analysis of 1010 people where the rule base was determined by expert knowledge. The criteria group recorded to show the highest performance in the Fuzzy Inference System (FIS) model application and the Adaptive NeuroFuzzy Inference System (ANFIS) method was applied to the same dataset to make a comparison.

\section{Materials and method}

\subsection{Region selection and formation of data set}

The study area included properties inside the central districts of the Konya Metropolitan area in Turkey, which constitutes approximately $10 \%$ of the residential area and has the most crowded residential density within the city. The study took as a basis an area that included nearly 8 neighborhoods and 320 real estate properties (Figure 1).

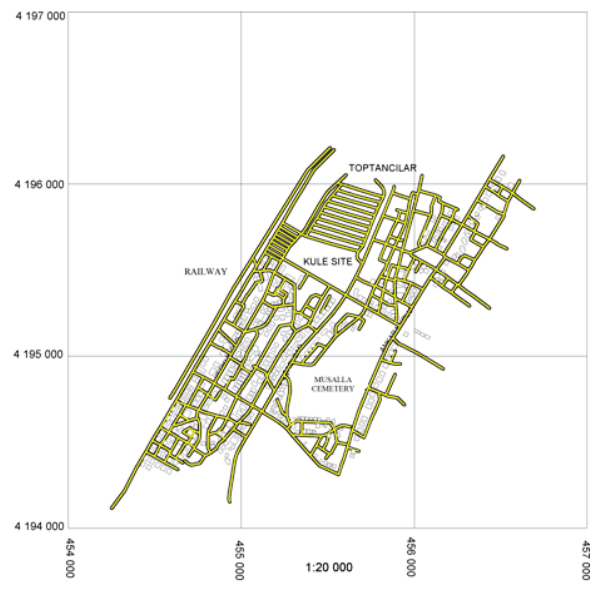

Figure 1. Study area
Figure 2a shows the study steps of ( $i$ ) development of criteria via questionnaire and (ii) creation of dataset while Figure $2 \mathrm{~b}$ shows workflow of FIS (Mamdani) and ANFIS (Sugeno) methods.

a)

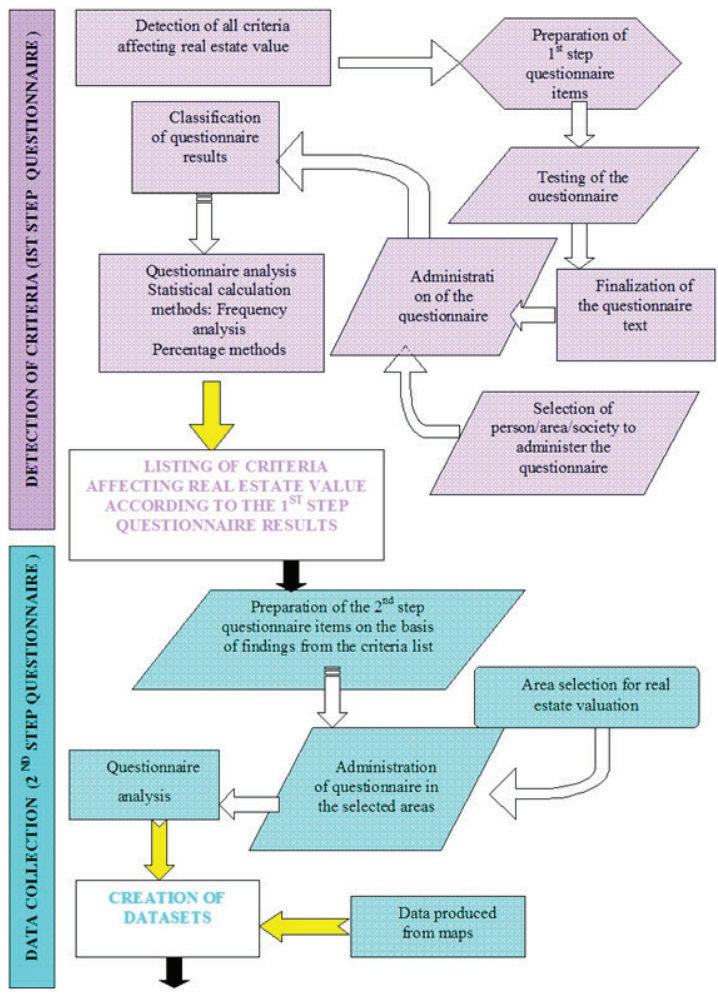

b)

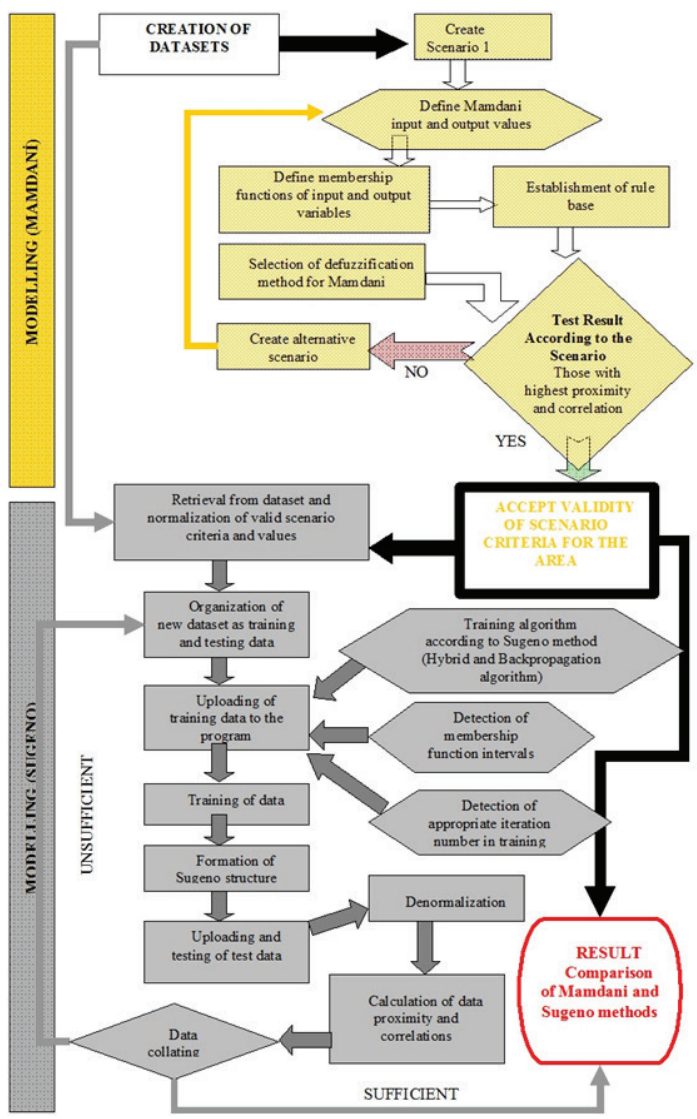

Figure 2. Study workflow scheme (a) questionnaire study; (b) modeling study 
The data set was established by using poll results. The poll was applied in two stages; the first stage was an analysis performed for the selection of the criteria affecting the value of real-estate (special attention was paid in this study to be objective rather than subjective in criteria selection within the scope of the questionnaire). Afterwards, a poll was taken of 1010 adults out of approximately 300,000 adults living in Konya. $10 \%$ of the questionnaire respondents were female and $90 \%$ male. Respondents of the first step questionnaire were generally in the 26-35 yeas-old range, had university education or higher education and were self-employed. The questionnaire was composed of questions asked in different styles that addressed 34 criteria. In addition, respondents were asked to answer fuzzy concepts related to area and distance to be used in the fuzzying part of the fuzzy model. For example:

Define the size concepts below for the actual usage area of a house you would buy.

1) Small: .... $m^{2}$; 2) Average: .... $m^{2}$; 3) Large: .... $m^{2}$; 4) Very Large: .... $m^{2}$.

The aim of this questionnaire was not to find out the extent to which personal preferences affect the price but to reveal the general criteria that is given the utmost attention in valuation of a real estate. Accordingly, answers given by 1010 respondents of the first questionnaire were evaluated to determine the criteria presented in Table 1. Using these criteria, the second step questionnaire study was initiated.

In the second stage, after forming the data set compatible with the criteria obtained in the poll study of the first stage, the incompatible data were removed; hence the data set involving the data of 120 real estate properties (out of 320 total in the region) became ready for the test. Real estate market values were collected from real estate agents. Because of the privacy policies of ownership rights, the registered private information could not be included in the data set. For this reason, some of the information was missing. The beneficial (shopping centers, school, transport, etc.) and harmful (noise, industrial zone, graveyard, etc.) criteria being together in the aforementioned districts played an effective role for the selection of the investigative area. The determined criteria were examined in detail by producing various scenarios and the most appropriate criteria set was obtained according to the dissertation at these Scenarios (Yalpır, 2007).

Since the input variables like floor condition, physical properties and real estate location were textual properties and difficult to express numerically, the poll results of these variables were scored to express these variables numerically. For instance, while a residential property at the fifth floor of a ten-story building was scored as 100, it was taken as 40 for the same property at the ground floor. Scores up to 100 were given for each criterion considered in the physical properties categories, and to get a single score value the arithmetical average was taken.

In order to assign the positional scores, first, the factors affecting the positional scores of the properties are determined considering the favorable factors as positive and unfavorable factors as negative. Then the properties positional scores were assigned as positive or negative (Table 2).

Table 1. Criteria used during modeling on the basis of first stage questionnaire results and characteristics of these criteria

\begin{tabular}{|l|l|l|l|}
\hline \multicolumn{1}{|c|}{ Criteria } & \multicolumn{1}{|c|}{ Characteristics } & Expression type & \\
\hline Housing area & $\begin{array}{l}\text { Areas within the building, which are reserved for family use and } \\
\text { excluded from common use area. }\end{array}$ & Numerical \\
\hline Age of the building & $\begin{array}{l}\text { Difference between the year of certificate of occupancy of the building } \\
\text { (where the flat is located) and valuation year }\end{array}$ & Numerical \\
\hline Floor condition & $\begin{array}{l}\text { Total storey number of the building and the floor of the flat (excluding } \\
\text { ground floor) }\end{array}$ & Numerical \\
\hline Physical properties & $\begin{array}{l}\text { Easy to use in-flat and out-of-building accessories and properties built } \\
\text { for comfort purposes such as cabinets, floor coverings, wall coverings, } \\
\text { external siding, etc. }\end{array}$ & Text \\
\hline Front of the flat & Front of the flat according to the building & Text \\
\hline Positional Score & Flat score calculated on the basis of environmental factors & Text \\
\hline Width of the street & Width of the street (in meter) in front of the flat & Numerical \\
\hline Market value & Flat value (in TL) according to market conditions & Numerical & Output \\
\hline
\end{tabular}

Table 2. Criteria considered in calculating positional score and resulting scores

\begin{tabular}{|l|l|c|}
\hline \multicolumn{1}{|c|}{ Criteria } & \multicolumn{1}{c|}{ Characteristics } & \multicolumn{1}{c|}{ Score } \\
\hline Distance to transport network & Between 0-50 $\mathrm{m}$ & 40 \\
\hline Distance to shopping centers & & 40 \\
\hline Distance to schools, healthcare centers, open space areas, worship places & If 4 of them are present & 10 \\
\cline { 2 - 3 } & If 2-3 of them are present & 7 \\
\cline { 2 - 3 } & If 1 of them is present & 5 \\
\hline Distance to railways & Between 0-50 m & -10 \\
\hline Distance to power transmission lines & & -10 \\
\hline Distance to cemeteries & & -10 \\
\hline
\end{tabular}


End of Table 2

\begin{tabular}{|l|l|c|}
\hline \multicolumn{1}{|c|}{ Criteria } & \multicolumn{1}{c|}{ Characteristics } & \multicolumn{1}{c|}{ Score } \\
\hline Distance to industrial zone & Between 0-100 m & -10 \\
\hline Distance to waste storage sites & & -10 \\
\hline Socio-cultural condition & Good & 10 \\
\cline { 2 - 3 } & Average & 5 \\
\cline { 2 - 3 } & Bad & -10 \\
\hline
\end{tabular}

\subsection{Modeling with Fuzzy Logic methodology}

Modeling with FIS: A model in Mamdani structure was built with FIS editor of Fuzzy toolbox in MATLAB 6.0 program. The determination of input and output variables (FIS structure) are indicated in Figure 3. In assigning the memberships, groups were formed by specifying the intervals. Common membership functions are triangular, bell curved and trapezoidal functions. The triangular function was selected as the main membership function of this study. The last memberships were transformed into trapezoidal function for some variables; if their ends were open i.e. if they were greater than the value of the last interval (Figure 4). The rule base was formed after assignment of the memberships. In the rule base, 85 rules were written as e.g., "IF area is greater AND age is less AND....THEN value is high". Some of these rules were presented Table 3.

In defuzzification, following the construction of the model with memberships and rule base, centroid, mean average, the highest membership average, the highest and the lowest membership methods were tested with data set and the best market value was reached with Centroid defuzzification method.

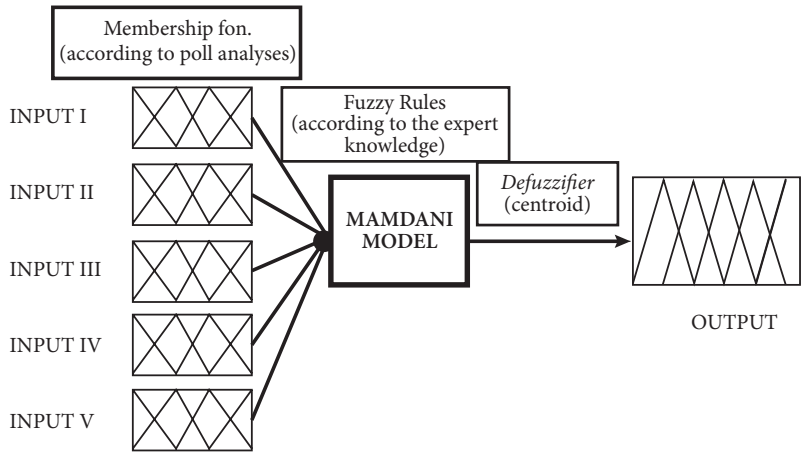

Figure 3. FIS structure in the study



Input 1 (Floor condition)

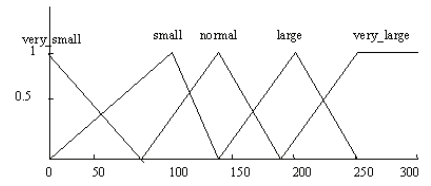

Input 3 (Area of the residential real-estate) Input 4(Physical properties)



Input 5 (Age of the building)

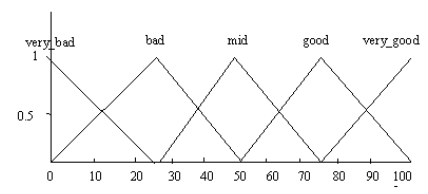

Input 2 (Positional score (Location))
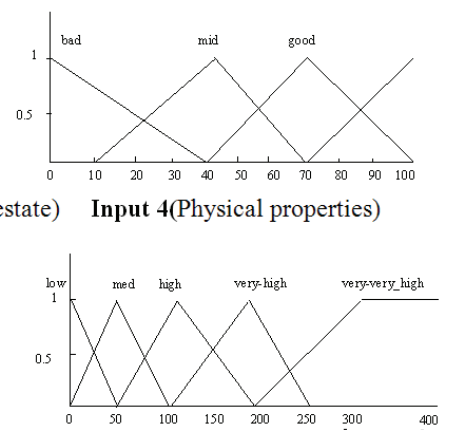

Output (Market value)
Figure 4. Memberships of input and output variables

The model developed in Mamdani structure and defined by obtaining the right number of criteria was used in Sugeno (ANFIS) structure.

Modeling with ANFIS: Criteria analysis was made using the model developed with FIS and FIS model with the most appropriate criteria was determined to evaluate the performance scores. These clarified criteria were used in ANFIS structure to make model comparisons.

As seen in the literature, the data had to be trained with approximately two-thirds of the data (80 data) and to be tested with the remaining one-third (40 data) (Brondino \& da Silva, 1999; Lokshina et al., 2003). Data were normalized in Sugeno for an easier and faster application. Normalization was applied by dividing the value to the highest/largest one of the data set.

Table 3. Rule base of the model

\begin{tabular}{|c|c|c|c|c|c|c|c|c|c|c|c|}
\hline & Area & & Age & & Floor & & $\begin{array}{l}\text { Physical } \\
\text { property }\end{array}$ & & Location & & Value \\
\hline \multirow[t]{5}{*}{ IF } & greater & \multirow[t]{5}{*}{ AND } & moderate & \multirow[t]{5}{*}{ AND } & top & \multirow[t]{5}{*}{ AND } & good & \multirow[t]{5}{*}{ AND } & moderate & \multirow[t]{5}{*}{ THEN } & moderate \\
\hline & normal & & less & & intermediate & & very good & & good & & high \\
\hline & greatest & & less & & intermediate & & very good & & very good & & highest \\
\hline & . & & . & & . & & . & & . & & . \\
\hline & . & & . & & . & & . & & . & & \\
\hline
\end{tabular}




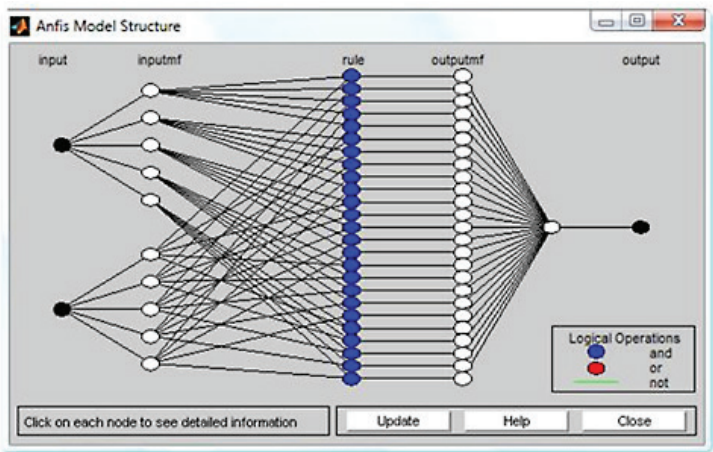

Figure 5. ANFIS operating structure

Cross validation was performed in the ANFIS application to test the whole dataset. According to the principles of the Sugeno method composed of 4 crosses, the structure of the ANFIS system was developed using 40 bellshaped curve membership functions (Figure 5).

\section{Statistical Evaluation of the Model Performance}

The model results were statistically analyzed using Mean Absolute Percentage Error (MAPE) (Equation (1)) and the standard deviation (SD) of MAPE was calculated by using the Equation (2).

$$
\begin{aligned}
& \text { MAPE }=\frac{\sum_{i=1}^{n}\left|\frac{x_{p}-x_{i}}{x_{p}}\right|}{n} * 100 \% \pm S D \% \\
& S D \%=\sqrt{\frac{\sum_{i=1}^{n}\left(M A P E_{i}-\overline{M A P E}^{2}\right.}{(n-1)}}
\end{aligned}
$$

where: $x_{p}$ is the market value; $x_{i}$ is the value of the Model structure; $i:\{1,2,3 \ldots n\} n$ : Total number of the residential properties in the data set; $y_{i}$ is Approximation value and $\bar{y}$ is the average of approximation value.

\section{Results and discussion}

This study aimed to define the optimum criteria effective on real estate value by using fuzzy logic methodology, to find the optimum criteria in the fuzzy logic Mamdani structure, test their applicability and finally make a comparison with the Sugeno method in ANFIS.

To estimate the real estate value, scenarios were created for optimum utilization of the 7 criteria obtained at the end of the first step questionnaire application.

120 data were used for modeling in Mamdani structure. Positional distribution of these data (which were used in modeling) in their own area was taken into consideration. Scenarios and their results based on these test data are listed in Table 4. Scenarios were begun using the minimum number of criteria produced at the end of the first step questionnaire and affecting the value of real estate and a second scenario was created on the ground of rational reasons. According to the scenarios presented in Table 4, the most appropriate structure seems to be Scenario E3 considering average approximation rates, standard deviations of average approximation rates, $\mathrm{R}^{2}$ and regression line equations.

In the model developed with FIS, performance scores of Scenario 3 were found to be higher than those of the remaining 5 scenarios. Accordingly, the criteria to be considered at optimum level in valuation of a residential real estate property were determined as follows:

- Area of the residential real estate.

- Age of the building.

- Floor condition.

- Physical properties.

- Positional score (Location).

Application of the model structure developed in Scenario 3 to 120 data produced the following average approximation score: Average Approximation percentage $=$ $86.66 \pm 9.57 \%$.

\begin{tabular}{|c|c|c|c|c|c|}
\hline Scenarios & MAPE & $\mathrm{SD} \%$ & $\mathrm{R}^{2}$ & $\begin{array}{l}\text { Best fit line } \\
\text { equation }\end{array}$ & \\
\hline $\begin{array}{l}\text { Scenario E1 } \\
\text { Housing area } \\
\text { Age of the building } \\
\text { Floor condition } \\
\text { Physical properties }\end{array}$ & 75.32 & \pm 23.04 & 0.6921 & $y=1.0746^{\star} x$ & \\
\hline $\begin{array}{l}\text { Scenario E2 } \\
\text { Housing area } \\
\text { Age of the building } \\
\text { Floor condition } \\
\text { Positional score }\end{array}$ & 83.66 & \pm 11.62 & 0.7142 & $y=0.9354^{\star} x$ & $\begin{array}{l}\text { To reflect positional effect to the criteria, positional } \\
\text { scores were included in and physical properties } \\
\text { were excluded from the criteria }\end{array}$ \\
\hline $\begin{array}{l}\text { Scenario E3 } \\
\text { Housing area } \\
\text { Age of the building } \\
\text { Floor condition } \\
\text { Physical properties } \\
\text { Positional score }\end{array}$ & 85.67 & \pm 10.39 & 0.8645 & $y=0.9932^{\star} x$ & $\begin{array}{l}\text { Regarding Scenario E1 and Scenario E2; average } \\
\text { approximation rates and } \mathrm{R}^{2} \text { results were calculated } \\
\text { to be close; and positional score and properties } \\
\text { score were found to be the same. For this reason } \\
\text { both criteria were included. }\end{array}$ \\
\hline
\end{tabular}

Table 4. Performances of the scenarios created in FIS model 
End of Table 4

\begin{tabular}{|c|c|c|c|c|c|}
\hline Scenarios & MAPE & SD\% & $\mathrm{R}^{2}$ & $\begin{array}{l}\text { Best fit line } \\
\text { equation }\end{array}$ & \\
\hline $\begin{array}{l}\text { Scenario E4 } \\
\text { Housing area } \\
\text { Age of the building } \\
\text { Floor condition } \\
\text { Internal properties } \\
\text { External properties } \\
\text { Positional score }\end{array}$ & 80.84 & \pm 15.41 & 0.7803 & $y=0.9743^{\star} x$ & $\begin{array}{l}\text { Physical properties were divided into two as the } \\
\text { properties of the flat and of the building, thus, the } \\
\text { number of criteria increased to } 6 \text { after inclusion of } \\
\text { internal and external properties. }\end{array}$ \\
\hline $\begin{array}{l}\text { Scenario E5 } \\
\text { Housing area } \\
\text { Age of the building } \\
\text { Floor condition } \\
\text { Internal properties } \\
\text { External properties } \\
\text { Front score } \\
\text { Positional score }\end{array}$ & 78.69 & \pm 18.16 & 0.7789 & $y=1.0404^{\star} x$ & $\begin{array}{l}\text { Due to the climate characteristics of the study area, } \\
\text { it was considered appropriate to include front score. }\end{array}$ \\
\hline $\begin{array}{l}\text { Scenario E6 } \\
\text { Housing area } \\
\text { Age of the building } \\
\text { Floor condition } \\
\text { Physical properties } \\
\text { Positional score } \\
\text { Width of the street }\end{array}$ & 78.98 & \pm 14.35 & 0.6884 & $y=0.9284^{\star} x$ & $\begin{array}{l}\text { According to the average approximation rates and } \\
\mathrm{R}^{2} \text { results of Scenario E4 and E5, positional score } \\
\text { and properties score used in Scenario E3 were } \\
\text { concluded to be necessary, and width of the street } \\
\text { was included in these criteria. }\end{array}$ \\
\hline
\end{tabular}

These five criteria, which were found to be the most successful criteria of FIS model, were applied to ANFIS. Resulting 3 cross validation results are presented in Table 5 .

Table 5. ANFIS cross validation results

\begin{tabular}{|l|c|c|}
\hline \multicolumn{1}{|c|}{ Cross } & Average approximity, \% & $\begin{array}{c}\text { Standard } \\
\text { Deviation }\end{array}$ \\
\hline $1^{\text {st }}$ cross & 72.47 & \pm 20.94 \\
\hline $2^{\text {nd }}$ cross & 74.76 & \pm 30.55 \\
\hline $3^{\text {rd }}$ cross & 81.01 & \pm 18.36 \\
\hline
\end{tabular}

Performance analysis made by combining the cross validation results obtained from ANFIS results produced the following: Average Approximation percentage = $77.75 \pm 20.74 \%$.

According to the models' performance results success rates varied in the $77-97 \%$ range for the FIS model and $57-98 \%$ range for the ANFIS model. These performance ratios showed that the FIS model's estimation range of is more successful than that of the ANFIS model.

The best regression curve was constructed to obtain the accuracy between the collected market values and the calculated output with a curve fitting (best line with $y=x$ line) with $45^{\circ}$ angle passing through origin as seen in Figure 6. The best curve fitting with zero intercept $(y=a x$ line) was used to define the level of accuracy between the collected market values and the models. For all models the slopes of the best fits are all close to 1 in the data set. However, the $R^{2}$ of ANFIS model is negative. This resulted from the failure of the ANFIS estimation value to fully overlap with market values.
A regression coefficient between the market value and the FIS value of 1 and the $45^{\circ}$ slope indicated the high approximation of the model to market values. The $R^{2}$ value of 0.84 was obtained as proof of the successful prediction level. In the literature, a deviation value was not reported for this type of study. Therefore, since the model results were statistically accurate, the model built in this study using the fuzzy logic method based on expert knowledge and poll analysis is highly promising to overcome the subjective character of the real estate valuation.

The established models were verified with the data obtained for 120 properties inside the investigation area. The models' predictions are indicated comparatively with the corresponding market values in Figure 7.

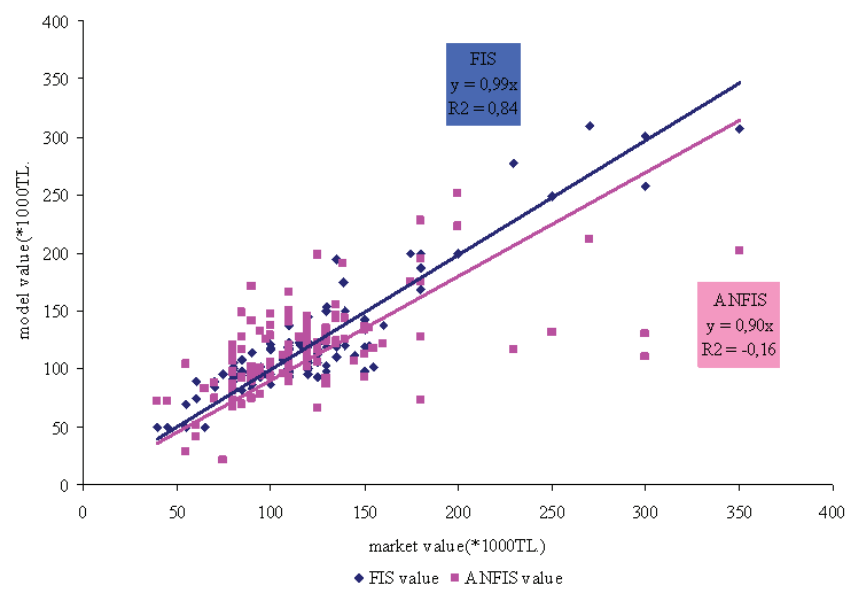

Figure 6. The regression line between the unit market values and model values 


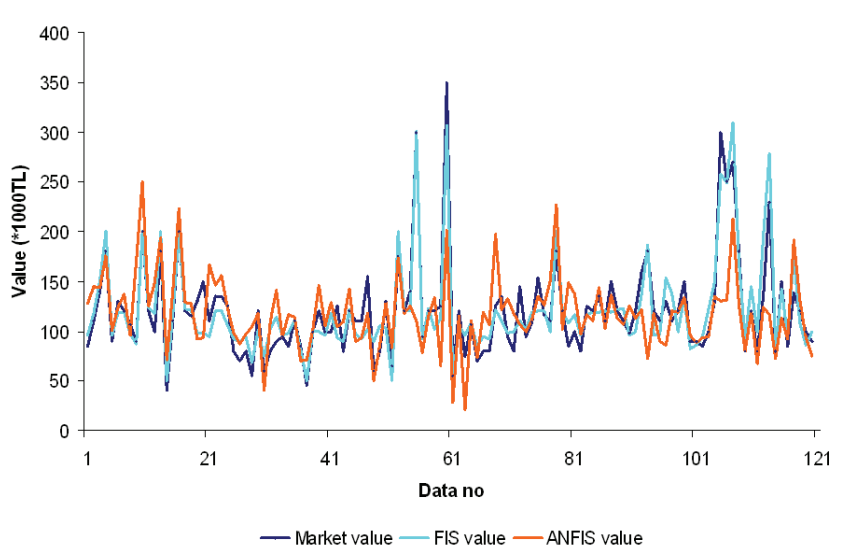

Figure 7. Comparison of estimated value of models and market values

Model output with FIS was at an acceptable level despite all these factors. Its prediction performance at the maximum and minimum values was strikingly more successful compared to the middle values than the value of ANFIS model.

\section{Conclusion}

In the real estate valuation process, the application of artificial intelligence models based on training and testing of the real estate data usually produce output limited to the characteristics of the data set; even though they generate considerably low error levels, the models will have limitations in the real marketing conditions with high variability.

Mamdani fuzzy inference system based on expert knowledge has many advantages in real estate valuation, which possesses a high level of subjective factors based on human perception. The system needs no training with data set limiting the applicability of the model.

Non-numeric characteristics such as floor condition, positional score, etc., render real estate valuation more complex. During the estimation of real-estate values with Mamdani, it was possible to use various alternatives for the stages of selecting factors that affect the value of the properties, assigning memberships, formation of rule base and estimation of the result value. Therefore, poll results are important to build the membership and rule base is for the expert knowledge. As the value range needs to be flexible, it will be most appropriate to obtain fuzzy inference in Mamdani structure. Since the Sugeno approach produces a single output dependent on variables in the output space, the market value can be reached in Mamdani with fuzzy outputs. Mamdani proved a reliable method to model the real estate valuation considering the human-originated variability. The Mamdani approach structured in the study can be applied in either governmental or private applications, wherever the real estate value is required.

The results showed that the produced FIS model is highly promising for the market conditions over ANFIS. The predicted values with FIS closely approached the real market values. The deviation remained at a very low level compared to the real market value, mostly originating from incompatibility of the data set. For example, criteria (inputs) tend to increase the market value, but, in real marketing conditions, real estate can be sold for a lower value due to emergency demand and supply conditions, or on the contrary, a higher selling price can occur despite some devaluing criteria value.

\section{Acknowledgement}

This work was financially supported by the Coordinatorship of Selcuk University’s Scientific Research Projects.

\section{References}

Bonisssone, P. P., \& Cheetham, W. (1997). Financial applications of fuzzy case-based reasoning to residential property valuation. Proceedings of the $6^{\text {th }}$ IEEE International Fuzzy Systems Conference (pp. 37-44), 5 July 1997. Barcelona, Spain. https://doi.org/10.1109/FUZZY.1997.616341

Brondino, N. C. M., \& da Silva, A. N. R. (1999). Combining artificial neural networks and GIS for land valuation process. Paper presented at the $6^{\text {th }}$ International Conference on Computers in Urban Planning and Management, 8-11 September 1999. Venezia, Italy.

Din, A., Hoesli, M., \& Bender, A. (2001). Environmental variables and real estate prices. Urban Studies, 38(11), 1989-2000. https://doi.org/10.1080/004.209.80120080899

Fischer, D. (2008). Evolution with teleology: the genetic programming heuristic approach to modeling. Journal of Real Estate Literature, 16(3), 345-362.

Fischer, D., \& Lai Pi-Ying, P. (2008). Land price modeling with genetic algorithms and artificial neural network procedures. Proceedings of the $14^{\text {th }}$ Annual Conference of the Pacific Rim Real Estate Society (pp. 1-9), 20-23 January 2008. Kuala Lumpur, Malaysia.

Gonzalez, M. A. S. (2008). Developing mass appraisal models with fuzzy systems. İn T. Kauko \& M. d'Amato (Eds.), Mass appraisal methods: an international perspective for property valuers (pp.181-202). Oxford: Wiley-Blackwell. https://doi.org/10.1002/978.144.4301021.ch9

Heine, K. (2001). Potential application of fuzzy methods in geodetic fields. Proceedings of the First International Symposium on Robust Statistics and Fuzzy Techniques in Geodesy and GIS (pp. 87-93), 12-16 March 2001. Zürich, Switzerland.

Ho, D. W. C., Zhang, P. A., \& Xu, J. (2001). Fuzzy wavelet networks for function learning. IEEE Transactions on Fuzzy Systems, 9(1), 200-211. https://doi.org/10.1109/91.917126

IVS. (2005). International Valuation Standards (IVS) (7th ed.). International Valuation Standards Council.

Kontrimas, V., \& Verikas, A. (2010). The mass appraisal of the real estate by computational intelligence. Applied Soft Computing, 11(1), 443-448. https://doi.org/10.1016/j.asoc.2009.12.003

Kusan, H., Aytekin, O., \& Özdemir, I. (2010). The use of fuzzy logic in predicting house selling price. Expert Systems with Applications, 37, 1808-1813. https://doi.org/10.1016/j.eswa.2009.07.031

Lewis, O. M., Ware, J. A., \& Jenkins, D. H. (2001). Identification of residential property sub-markets using evolutionary and neural computing techniques. Neural Computing \& Applications, 10, 108-119. https://doi.org/10.1007/s005.210.170003 
Lokshina, I. V., Hammerslag, M. D., \& Insinga, R. C. (2003). Applications of artificial intelligence methods for real estate valuation and decision support. Hawaii International Conference on Business, 18-21 June 2003. Honolulu, Hawaii, USA.

Mak, S., Choy, L., \& Ho, W. (2010). Quantile regression estimates of Hong Kong real estate prices. Urban Studies, 47(11), 24612472. https://doi.org/10.1177/004.209.8009359032

Mamdani, E. H., \& Assilian, S. (1975). An experiment in linguistic synthesis with a fuzzy logic controller. International Journal of Man-Machine Studies, 7(1), 1-13. https://doi.org/10.1016/S0020-7373(75)80002-2

Mert, Z. G., \& Yilmaz, S. (2009). Fuzzy modeling approach based on property location quality for grading neighborhood level of family housing units. Expert Systems with Applications, 36, 3603-3613. https://doi.org/10.1016/j.eswa.2008.02.023

Pagourtzi, E., Assimakopoulos, V., Hatzichristos, T., \& French, N. (2003). Practice briefing real estate appraisal: a review of valuation methods. Journal of Property Investment \& Finance, 21(4), 383-401. https://doi.org/10.1108/146.357.80310483656

Sarip, A. G., \& Hafez, M. B. (2015). Fuzzy logic application for house price prediction. International Journal of Property Sciences, 5(1), 24-30.

Sarip, A. G., Hafez, M. B., \& Daud, Md. N. (2016). Application of fuzzy regression model for real estate price prediction. Malaysian Journal of Computer Science, 29(1), 15-27. https://doi.org/10.22452/mjcs.vol29no1.2
Sen, Z. (2001). Fuzzy logic and modeling principles. Bilge Art Production Pub. Rec. Pap. Tourism Industry Trading Limited Company. Istanbul.

Sygnowski, M., Trawinski, B., \& Zgrzywa, A. (2008). An attempt to use a type-2 fuzzy logic system to assist with real estate appraisals. Proceedings of the $1^{\text {st }}$ International Conference on Information Technology (pp. 19-21), 18-21 May 2008. Gdansk, Poland. https://doi.org/10.1109/INFTECH.2008.462.1620

Takagi, T., \& Sugeno, M. (1985). Fuzzy identification of systems and its applications to modeling and control. IEEE Transactions on Systems, Man, and Cybernetics, 15(1), 116-132. https://doi.org/10.1109/TSMC.1985.631.3399

Yalpir, S. (2007). Bulanık mantık metodolojisi ile taşınmaz değerlenme modelinin geliştirilmesi ve uygulaması. Konya Örneği, $\mathrm{PhD}$ Dissertation (in Turkish). Selcuk University, Konya.

Yalpir, S., \& Ozkan, G. (2008). The usage of artificial intelligence in determining the residential real-estate prices in urban areas and the comparison of valuation methods. Integrating Generations FIG Working Week 2008, 14-19 June 2008. Stockholm, Sweden.

Yalpir, S., \& Ozkan, G. (2011). Fuzzy logic methodology and multiple regression for residential real-estates valuation in urban areas. Scientific Research and Essays, 6(12), 2431-2436. 